\title{
Determination of the properties of acoustic materials - airflow resistance of cellulose based insulation material
}

\author{
Pavel Rubáśs, ${ }^{1,}$, Jaroslav Výborný ${ }^{2}$ \\ ${ }^{1}$ Technical and Test Institute for Constructions Prague, Prosecká 811/76a, Praha 9, Czech Republic \\ ${ }^{2}$ Czech Technical University in Prague, Faculty of Civil Engineering, Thákurova 7/2077, 16629 \\ Praha 6 Dejvice, Czech Republic
}

\begin{abstract}
The air flow resistance is a fundamental acoustic parameter to understanding the properties of cellulose based insulation material, it is useful for research and development to perform acoustic performance prediction and for calculation modelling. There is a connection between structure of cellulose based insulation material and its acoustic characteristics. Specific air flow resistance is also a parameter for the quality of cellulose based insulation which is used for factory production control because there is also strong connection between specific air flow resistance and density of produced material. Experimental measurement of airflow resistance has been performed according to the direct method of the EN 29053 standard where low and constant air flow is passed through cellulose based insulation with a specific section.
\end{abstract}

\section{Introduction}

In noise control engineering, airflow resistance is the most important input parameter for estimating sound absorption for porous type absorbers. It is defined as the ratio of the pressure drop to the airflow velocity through a test sample. The airflow resistance could effectively describe the resistance effects of air passed through a fibrous material. Airflow resistance $r\left[\mathrm{~Pa} \cdot \mathrm{s} \cdot \mathrm{m}^{-2}\right]$ is the inverse value to the airflow coefficient of the material $r^{-1}$ $\left[\mathrm{m} 3 \cdot \mathrm{Pa}^{-1} \cdot \mathrm{m}^{-1} \cdot \mathrm{s}^{-1}\right]$. The airflow coefficient of a material is a less widespread but more understandable quantity compared to airflow resistance. The airflow coefficient is defined as the volume of air $\left(\right.$ in $\mathrm{m}^{3}$ ) that flows in one second through a $1 \mathrm{~m}^{2}$ area of a porous material $1 \mathrm{~m}$ thick at a pressure difference between the two surfaces of $1 \mathrm{~Pa}$. In this concept, airflow resistance $r$ is a quantity describing the resistance put to the air flow by the embedded material at a pressure difference of $1 \mathrm{~Pa}$ between the two ends.

Over the years, in many papers and books the knowledge of the physical properties of porous and fibrous materials has been studied but there is no specific research of airflow resistance of cellulose based insulation materials [3-5]. However, the airflow resistance sensitivity of cellulose based insulation material to material characteristics, particularly the specific weight, seems to be less known, at least from an experimental point of view.

*Corresponding author: rubas@tzus.cz 
Measurements are carried out by using an apparatus specifically designed to measure the airflow resistance of cellulose based insulation materials. In this article a simple formula for the prediction of the airflow resistance as a function of the specific weight of cellulose based insulation is also proposed.

\section{Meaning and measurement}

Airflow resistance $r$ of a porous material is an indirect expression of certain material structure properties. It may be used to define the relationship between the material's structure and certain acoustic properties (in particular sound absorption and attenuation). This quantity is measured as described in the European standard EN 29053:1994 Acoustics. Materials for acoustical applications - Determination of airflow resistance. As mentioned in the introduction, airflow resistance $r$ is the ratio of the pressure difference $[\mathrm{Pa}]$ on the two sides of a test sample to the volumetric air flow rate through the test sample $\left[\mathrm{m}^{3}\right]$. The normalised airflow resistance $R_{s}$ is the product of the airflow resistance $R\left[\mathrm{~Pa} \cdot \mathrm{s} \cdot \mathrm{m}^{-3}\right]$ and the cross-sectional area of the test sample perpendicular to the airflow direction [1].

The airflow resistance $R$ is related to the normalised airflow resistance $R_{s}\left(\mathrm{~Pa} \cdot \mathrm{s} \cdot \mathrm{m}^{-1}\right)$ by the formula:

$$
R_{s}=R \cdot A
$$

where $A$ is the cross-sectional area of the test sample $\left[\mathrm{m}^{2}\right]$ perpendicular to the airflow direction

Airflow resistance $r\left[\mathrm{~Pa} \cdot \mathrm{s} \cdot \mathrm{m}^{-2}\right]$ is the normalised airflow resistance divided by the sample thickness:

$$
r=R_{s} \cdot d^{-1}
$$

where $d$ is the sample thickness in metres (measured in the air flow direction)

The test standard EN 29053 [1] describes two quite different test methods. The direct airflow method (Method A) is conventionally used in the Czech Republic. This method uses a controlled direct air flow through a cylindrical or rectangular test sample, and measures the pressure drop between the two free sample faces (see Figure 1) 


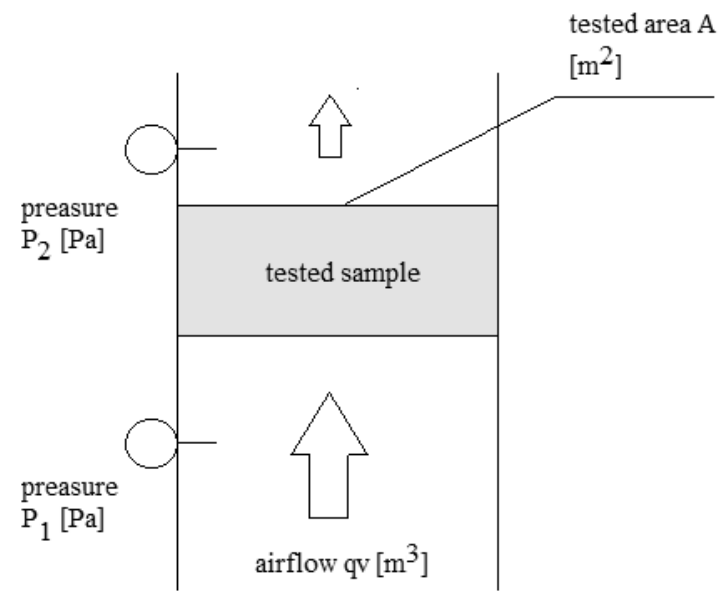

Fig. 1. Method A measuring principle

\section{Tested materials}

Cellulose insulation is often made by hammer milling waste paper. The paper is treated with chemicals, such as boric acid, to retard the spread of fire. Dry cellulose based insulation is used in retrofitting old homes by blowing the cellulose into holes drilled into the tops of the walls. It can also be blown into a new wall construction by using temporary retainers or netting that is clamped in place then removed once the cellulose has reached the appropriate density. Various samples of cellulose insulation were prepared with specific weight from 10 to $100 \mathrm{~kg} \cdot \mathrm{m}^{3}$. Six replicates of each sample were prepared and measured so that six values of flow resistance for each sample were obtained. The largest and smallest values are taken as the interval if the typical deviation was lower than 5\%. Fig 4 presents the results of airflow resistance for the all samples considered.

\section{Experimental tests and results}

Measuring equipment for method A (see Figure 2) consists of a measuring chamber where the test sample is installed, a device delivering a constant air flow, an air flow gauge, pressure gauges on both sides of the sample, and a thickness gauge. The test sample is installed in the measuring chamber, making sure that the sample edges are air tightly sealed. The precise specific weight of the test sample must be known. Within a certain range, the airflow resistance of a sound absorbing material increases with increasing air velocity, so the measurement should be carried out at the lowest possible velocity. Typically, $0.5 \times 10^{-3} \mathrm{~m} \cdot \mathrm{s}^{-1}$ is used as the lower air velocity limit. The acoustic pressure corresponding to this acoustic velocity at an air wave resistance of $400 \mathrm{~kg} \cdot \mathrm{m}^{-2} \cdot \mathrm{s}^{-1}$ is $0.2 \mathrm{~Pa}$ (expressed on the logarithmic scale, this is the sound pressure level $\mathrm{L}=80 \mathrm{~dB}$ at the reference acoustic pressure of $20 \mu \mathrm{Pa}$ ). 


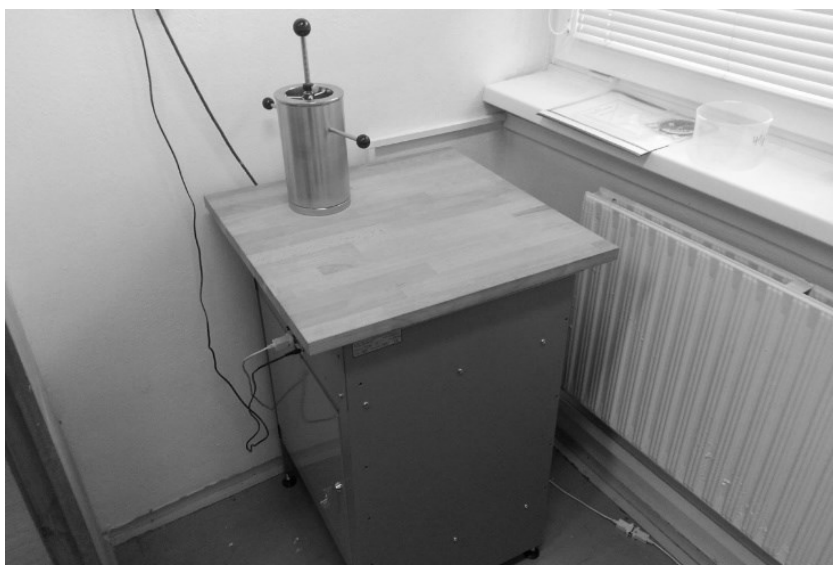

Fig. 2. Airflow resistance measuring equipment - Method A

The specific airflow resistance data are continuously calculated for various air velocities during the measurement. The dependence on air flow velocity is shown in Fig. 3, which illustrates real sample measurement with $r=1.69 \mathrm{kPa} \cdot \mathrm{s} \cdot \mathrm{m}^{-2}$. For instance, this corresponds to $\mathrm{r}^{-1}=0.59 \mathrm{~m}^{3} \cdot \mathrm{kPa}^{-1} \cdot \mathrm{m}^{-1} \cdot \mathrm{s}^{-1}$ for a cellulose based insulating material.

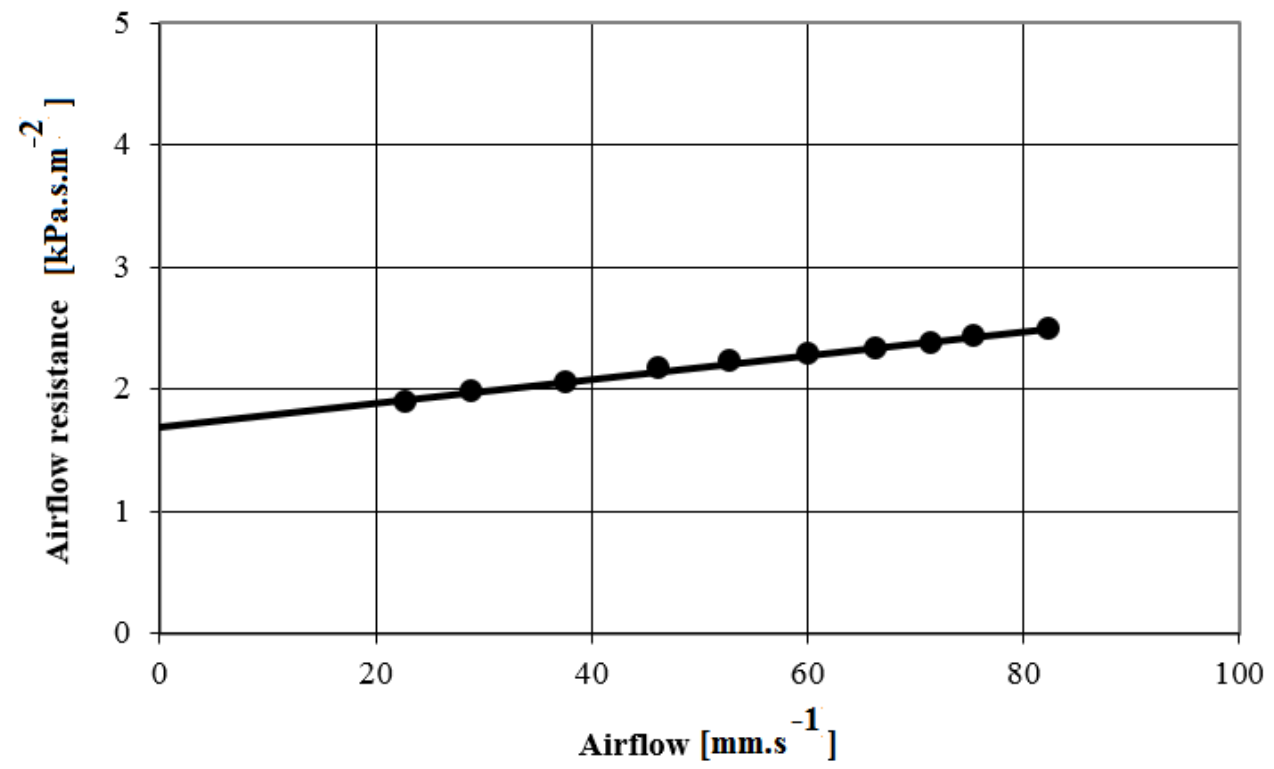

Fig. 3. Dependence on airflow velocity - example of cellulose based insulation $\rho=40 \mathrm{~kg} / \mathrm{m}^{3}$

Fig. 4 exhibits the interrelations between the basic qualitative parameters of cellulose based insulation (specific weight) and airflow resistance $r\left[\mathrm{~Pa} \cdot \mathrm{s} \cdot \mathrm{m}^{-2}\right]$. Heavy cellulose based insulation exhibits higher $r\left[\mathrm{~Pa} \cdot \mathrm{s} \cdot \mathrm{m}^{-2}\right]$. 


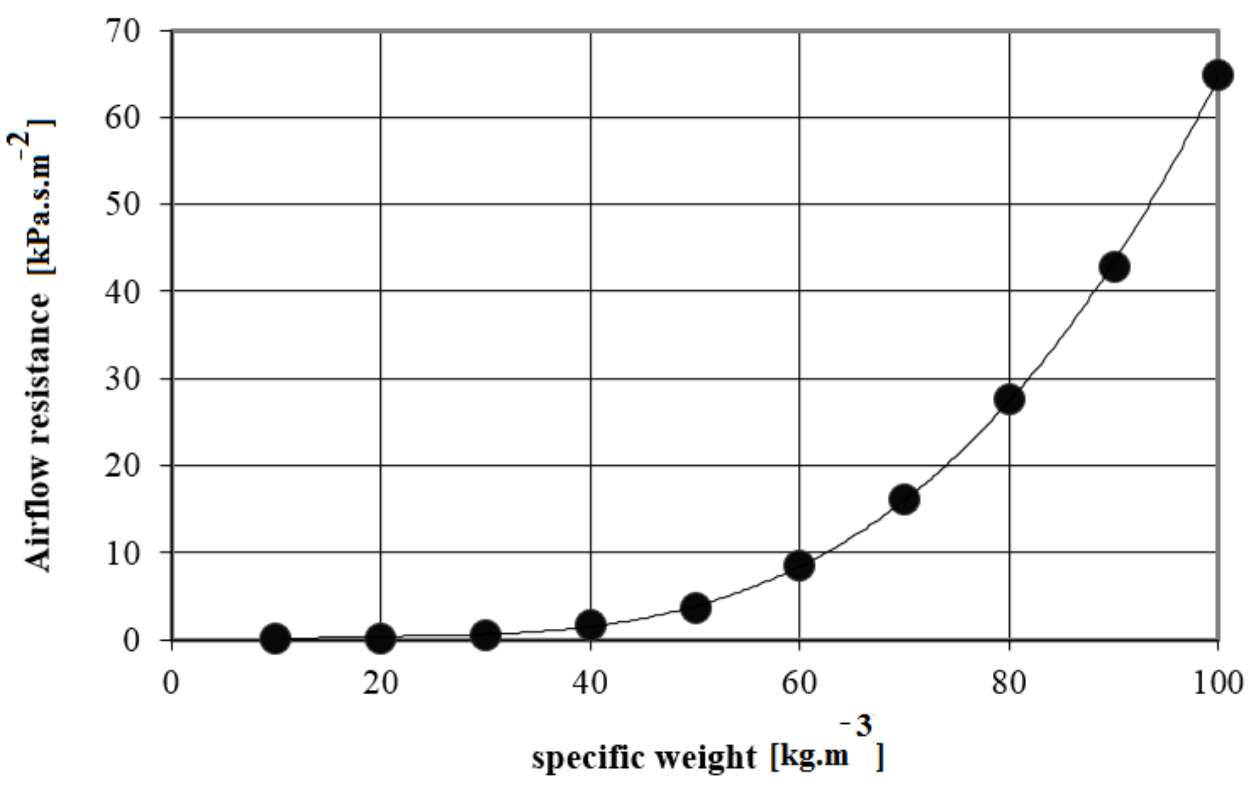

Fig. 4. Derived dependence of airflow resistance and specific weight of cellulose based insulation

\section{Conclusion}

In this paper, the airflow resistance performance of cellulose based insulation material has been investigated. Ten cellulose based insulation samples with different specific weight have been used. Airflow resistance measurements were carried out. From the measurements results, it has been demonstrated that the airflow resistance of cellulose based insulation depends on its specific weight.

Airflow resistance is a not very widespread parameter for insulation in the Czech Republic but its measurement and evaluation is required for the certification of cellulose based insulation because it affecting their sound absorbing coefficient. On the bases of experimental results, it can said that the airflow resistance $\mathrm{r}\left[\mathrm{Pa} \cdot \mathrm{s} \cdot \mathrm{m}^{-2}\right]$ of cellulose based insulation depends on its specific weight $\rho\left[\mathrm{kg} \cdot \mathrm{m}^{3}\right]$ according to the formula:

$$
r=0.07 \cdot e^{0.076 . \rho}
$$

where $\rho$ is the specific weight of cellulose based insulation $\left[\mathrm{kg} \cdot \mathrm{m}^{-3}\right]$

Figure 4 graphically shows the measured values of airflow resistance for cellulose based insulation material for different values of specific weight, the derived formula (3) is applicable for the prediction of the airflow resistance of cellulose based insulation with the specific weight from 10 to $100 \mathrm{~kg} \cdot \mathrm{m}^{-3}$. 


\section{References}

1. EN 29053:1994 Acoustics. Materials for acoustical applications - Determination of airflow resistance;

2. Leo L. Beranek, "Acoustic impedance of porous materials", J. Acoust. Soc. Am. 13, 1942 ;

3. R. L. Brown, R. H. Bolt, "The measurement of flow resistance of porous acoustic materials", J. Acoust. Soc. Am. 13, 1942;

4. D. A. Bies, "Acoustical properties of porous materials" in "Noise And Vibration Control (Revised Edition)" edited by Leo L. Beranek,1988;

5. A. F. Miguel, A. Serrenho, "On the experimental evaluation of permeability in porous media using a gas flow method”, J. Phys. D: Appl. Phys. 40, 2007. 